\title{
Esporte, geopolítica e relações internacionais
}

\author{
Sport, Geopolitics and International Relations
}

\author{
César Teixeira Castilho \\ Universidade Federal de Minas Gerais, Belo Horizonte/Brasil \\ Doutor em Sciences du Sport, Université Paris-Sud 11 \\ castcesarster@gmail.com
}

Wanderley Marchi Júnior

Universidade Federal do Paraná, Curitiba/Brasil Doutor em Educação Física, UNICAMP

Resumo: 0 objetivo deste artigo é analisar os possíveis diálogos existentes entre o esporte, a geopolítica e as relações internacionais. Trata-se de um estudo exploratório do tipo qualitativo, combinando as abordagens bibliográficas e documental de diferentes fontes e países de origem. Percebe-se, desde os Jogos Olímpicos Antigos, 776 a. C., uma correlação estreita entre as práticas esportivas e os interesses geopolíticos. Com o passar do tempo, tais aproximações tornaram-se mais indubitáveis, ditando tomadas de decisões dos órgãos responsáveis pelos megaeventos esportivos e fomentando o aparelhamento do esporte pelas nações através do conceito de soft-power. Embora estejam claro o diálogo e o uso do esporte como ferramenta geopolítica e de relações internacionais, análises contrabalanceadas e dialógicas devem ser realizadas para que certa relativização do fenômeno esportivo seja factível.

PalAVRAS-CHAVE: Esporte; Geopolítica; Relações Internacionais; Soft-Power.

ABSTRACT: This article's goal is to analyse possible interactions between sport, geopolitics and international relations. Based on an exploratory qualitative study, it combines the bibliographic and documentary approaches from different sources and countries of origin. Since the Ancient Olympics, in 776 BC, there has been a close correlation between sport practices and geopolitical interests. Over time, such approaches became even more clear, dictating the organizations responsible for sports mega-events' decision-making, and having Nations' promoting the infrastructure built for sports' through the concept of soft-power. Although the use of sport as a geopolitical and international relations' tool is clear, counterbalanced and dialogical analysis must be carried out in order to make certain relativization on the sport phenomenon feasible.

KEYWORDS: Sport; Geopolitics; International Relations; Soft-Power. 


\section{INTRODUÇÃo}

A ideia olímpica da Era Moderna simboliza uma guerra mundial, que não demonstra abertamente seu caráter militar, mas que oferece - para aqueles que sabem ler as estatísticas esportivas - um panorama suficiente da hierarquia das Nações (citação retirada de um jornal esportivo alemão de 1913). ${ }^{1}$

Os exercícios, as atividades e as competições esportivas são tão diversos e tão ricos que não podem ser reduzidos ou apresentados somente pelos detalhes. Certos esportes são individuais, outros coletivos. Alguns são limitados por uma região, um país, um continente, um espaço cultural, enquanto outros são quase universais. Existem práticas esportivas populares, facilmente e largamente praticadas, e outras ainda marcadamente aristocráticas, servindo como identidades sociais, ou elementos de distinção. ${ }^{2}$ Neste contexto, temos os Jogos Olímpicos (JO) apresentando o suprassumo mais complexo e universal, não obstante, o esporte não pode se reduzir às disciplinas que o compõem. Outrora, "o esporte era por definição uma atividade de proximidade, na medida em que poderíamos fazer uma analogia com a ironia expressa por Napoleão: o amor e a guerra só são possíveis pela presença do adversário". ${ }^{3}$ Atualmente, a distância não representa um empecilho, contemplamos o esporte de qualquer local e, a bem da verdade, poderíamos dizer que invariavelmente o contemplamos mais que o praticamos. 0 esporte tornou-se um fenômeno internacional, componente das relações internacionais. De um lado, sociedade transnacional, por outro lado, instrumento de paz e "guerra" entre nações.

Espontaneamente, a associação entre o esporte e a geopolítica não nos parece tão evidente. 0 primeiro nos remete a um objeto popular e frequentemente vinculado a certa frivolidade, enquanto o segundo termo, evoca uma correlação com a leitura e a compreensão da complexidade do mundo e as inúmeras relações entre seus atores, seus protagonistas. Deste modo, é preciso se inscrever na linha de pensamento de Pierre Milza, autor do livro Sport et Relations Internationales,

\footnotetext{
${ }^{1}$ GILLON. Une lecture géopolitique du système olympique, p. 1. (Tradução do autor).

2 BOURDIEU. A distinção: crítica social do julgamento, s/ pág.

${ }^{3}$ GUÉGAN. Géopolitique du sport, une autre explication du monde, p. 77.
} 
para que possamos pensar no esporte contemporâneo. ${ }^{4}$ Para o autor, o esporte é bem mais que um jogo, vai além de uma vitória ou de uma derrota. 0 esporte, enquanto campo, é o mundo em miniatura, ele possui suas especificidades, suas crises e seus sucessos. Ele está inserido no meio social e é seu reflexo.

Fenômeno de massa, presente atualmente em todas as partes do planeta, atravessado por todas as ideologias do século, indicador de soberania e declínio das Nações, ora revelador, ora manipulador do sentimento público, substituto da guerra e instrumento de diplomacia, o esporte é o centro da vida internacional. Mas é igualmente seu constituinte, um reflexo da vida internacional e um meio de política de relações exteriores. ${ }^{5}$

No mesmo sentido interpretativo do esporte na contemporaneidade, encontramos uma leitura polissêmica a qual favorece uma melhor contextualização desse fenômeno social e suas possíveis interconexões funcionais:

O esporte é compreendido como um fenômeno processual físico, social, econômico e cultural, construído dinâmica e historicamente, presente na maioria dos povos e culturas intercontinentais, independentemente da nacionalidade, língua, cor, credo, posição social, gênero ou idade, e que na contemporaneidade tem se popularizado globalmente e redimensionado seu sentido pelas lógicas contextuais dos processos de mercantilização, profissionalização e espetacularização. ${ }^{6}$

Diante disso, neste artigo, pretendemos expor os diálogos já construídos e aqueles que ainda despontarão entre o campo esportivo, a geopolítica e as relações internacionais. Como exemplo dessa possível inter-relação, já nos Jogos Antigos, 776 a. C., era possível perceber o poder do esporte nas relações entre as cidades gregas. Segundo pesquisadores do tema, existem evidências de "compras" de atletas entre regiões gregas como forma de publicidade de uma localidade em detrimento de outra. Estes atletas, tal qual observamos nos dias de hoje, eram tidos como traidores e desleais. ${ }^{7}$

\footnotetext{
${ }^{4}$ MILZA. Sport e t relationsinternacionales, sem página.

${ }^{5}$ MILZA. Sport e $t$ relations internacionales, p. 152. (Tradução do autor).

${ }^{6}$ MARCHI JR. O "esporte em cena", p. 69.

${ }^{7}$ GOLDBLATT. The Games, a global history of the Olympics, sempágina.
} 


\section{ESPORTE, HISTÓRIA E RELAÇÕES INTERNACIONAIS: GUERRAS E RIVALIDADES POR OUTROS MEIOS}

O esporte pode revelar as relações internacionais. Nele encontramos as oposições, as composições, suas estruturas e seus atores principais. Por meio dele, as Nações se mostram para o mundo, através das suas convergências e/ou divergências. Quer seja, por exemplo, pelos boicotes dos JO de Moscou (1980), ou aqueles dos J0 de Los Angeles (1984), ou ainda pensando na disputa pelas medalhas douradas durante a Guerra Fria a qual representa o maior sinal de oposição irredutível entre as duas grandes potências globais e seus modelos antagonistas no contexto de confrontação em escala mundial perdurando mais de quarenta anos. ${ }^{8}$

A história está pejada de utilizações, de recuperação e de difusão do esporte com fins geopolíticos com uma multiplicidade de exemplos remarcáveis (Guerra Fria, Primavera Árabe, a questão da Palestina, Ilhas Malvinas, entre outros). Que seja um detentor de uma unidade nacional nos estádios ${ }^{9}$ ou um orgulho ferido de populações ameaçadas, o esporte possui uma ligação direta com os povos, com suas histórias e, evidentemente, com as relações entre os estados-nações.

O campo esportivo porta uma historicidade e memórias próprias que revelam seus homens, suas histórias e seus poderes que o organizam e o dirigem. Ao se constituir desta forma, o esporte oferece espaço para que diferentes partes do mundo utilizem do seu território - ou tabuleiro mundial - para manipular ou jogar suas relações internacionais, suas relações exteriores. Tal situação é tanto mais verdadeira que, nas modalidades esportivas de confronto direto entre os oponentes, a disputa é representada frequentemente como um simulacro militar ou como um substituto da guerra, ou seja, uma maneira de prolongar a diplomacia e as rivalidades entre seus protagonistas por outros meios.

\footnotetext{
8 GUÉGAN. Géopolitique du sport, une autre explication du monde, s/ pág. GYGAX. Diplomatique culturelle et sportive américaine, s/ pág.

${ }^{9}$ BOLZ. Lesarènestotalitaires, s/ pág. Sobre este assunto, sugerimos a leitura do livro Les arènes totalitaires: Hitler, Mussolini et lês jeux du stade (BOLZ, 2008), no qual a autora discute a arquitetura dos estádios e suas apropriações na gênese da "religião fascista" na primeira metade do século XX.
} 


\section{ESPORTE, ENTRE DESENVOLVIMENTO E PODER: UM REVELADOR GEOPOLÍTICO}

Graças ao seu prestígio econômico enquanto setor de atividade e sua importância nas diversas sociedades globais, em termos de empregos, atores econômicos e empresas especializadas, o esporte é um indicador da potência econômica e financeira de um estado. Ele posiciona igualmente seu nível de maturação e de integração na mundialização das trocas comerciais. As tabelas de classificação de diferentes modalidades mundiais saltam aos olhos, salvo certas exceções, como a Índia, a hierarquia econômica das potências globalizadas.

A China investe no esporte e, através disto, se distingue desde sua emergência e seus frutos gerados pelas reformas de modernização e sua política de abertura internacional presidida por Deng Xiaoping, ${ }^{10}$ em 1979. A África do Sul conhece a mesma situação. Suas vitórias esportivas a posicionaram numa posição de destaque no cenário internacional. Marcando sua nova dimensão econômica e com o fim do apartheid, os triunfos esportivos no rúgbi, e em outras modalidades, contribuíram para que a nação "Arco-Íris" se transformasse em um estado mais turístico e capaz de financiar suas palmas no esporte através do seu crescimento concomitante. Sua situação financeira atual, caracterizada pela recessão econômica, também reflete na performance da sua equipe fetiche, os Springboks. ${ }^{11}$ Já há algum tempo, a equipe nacional de rúgbi parece "patinar" no cenário mundial.

O esporte demonstra a capacidade de uma sociedade e de seus atores no investimento financeiro, institucional e social, gerando possíveis benefícios. Ele sinaliza qual o grau de maturidade econômica e política de uma nação, mas igualmente seu nível de progresso e de organização, por ser capaz de mobilizar recursos que vão além dos interesses inerentes ao esporte. Neste aspecto, o esporte é um revelador estratégico do desenvolvimento social e político dos seus protagonistas. Em todas as etapas, e no curto e longo termos, a performance esportiva não é obtida somente pelo talento dos atletas ou pelo campeão por

\footnotetext{
${ }^{10}$ Deng Xiaoping (1904 - 1997), foi líder supremo da República Popular da China entre 1978 e 1992. Neste período, introduziu diversas medidas que caracterizaram a reforma econômica, conhecida como a "segunda revolução", responsável por um transformação completa do país (LACOSTE, 1999).

${ }^{11}$ Apelido dado à equipe de rúgbi sul-africana.
} 
exceção que surge, quando muito, ao longo de uma geração. 0 campo esportivo é um sistema institucionalizado, financiado e dirigido que pressupõe a capacidade de um país em selecionar, formar, educar e treinar sua juventude para que seja competitiva, localmente ou mundialmente.

Tendo como referência Raymond Aron, o esporte expõe como um ator (instituição) e valoriza o fator população, para que se possa transformá-lo em um fator decisivo. ${ }^{12}$ Por exemplo, o número de jogadores presentes entre os cem melhores no ranking da Associação Mundial de Tênis (ATP) demonstra a força das federações locais e possíveis imbricações em instituições privadas internacionais, tal qual academias de renome mundial, presença de técnicos estrangeiros, entre outros. Estes dados revelam igualmente uma relativa modernidade em uma determinada modalidade. 0 esporte ilustra a capacidade dos seus atores, notadamente oriundos do setor público, em organizar, difundir e institucionalizar o esporte em todas as camadas sociais. A reorganização do futebol alemão após o Mundial de 2002 e seus triunfos recentes oferece outro exemplo, bem como a exportação do modelo de formação do futebol espanhol em direção à Ásia. ${ }^{13}$ Neste mesmo sentido, a política voluntarista chinesa de investimento e de formação no rúgbi e futebol é um exemplo notável. Implementado por Xi Jinping, presidente chinês, e subvencionado pelos oligarcas do país, este projeto constitui uma ação eloquente nos campos do esporte, do desenvolvimento científico e geopolítico. ${ }^{14}$

Nesta perspectiva, outro constato se impõe: o esporte, através da sua pesquisa em performance, revela a capacidade científica e técnica de um país ao mesmo tempo que sua atratividade e seu alcance internacional. Ao permitir, facilitar e melhorar a performance dos atores esportivos (atletas e instituições), o que se evidencia é o poderio tecnológico e científico de um estado. A capacidade de inovação e de invenção integrada ao aporte científico de ponta revela-se como um fator de distinção entre as grandes potências permitindo catalisar recursos e

\footnotetext{
${ }^{12}$ ARON. Le spectateur engagé, sempágina.

${ }^{13}$ Diferentemente do Brasil que exporta seus jogadores ainda jovens e não um modelo de formação dos atletas. O Catar e a equipe catalã do FC Barcelona, através do futebol, estabeleceram parcerias importantes (patrocínio, troca de expertises, etc.). Com este intercâmbio, o Catar visava melhorar a qualidade do seu futebol - a equipe foi campeã da Copa da Ásia em 2019 de forma inédita -, enquanto a equipe espanhola se beneficiava através dos investimentos milionários (GINESTA e EUGENIO, 2013).

${ }^{14}$ GUÉGAN. Géopolitique du sport, une autre explication du monde, sempágina.
} 
estabelecer parcerias exteriores. A título de exemplo, podemos citar como o Emirado do Qatar vem investindo neste setor nos últimos anos, para além dos megaeventos esportivos (Tabela 1). 0 Aspire Complex, originalmente projetado para os Jogos Asiáticos de 2006, foi readaptado como um centro de treinamento de futebol (Football Dreams Program), além de ser o único centro médico credenciado pela FIFA no Oriente Médio.Incorporando dois hotéis cinco estrelas, um estádio com capacidade para 50.000 pessoas, uma piscina olímpica, e laboratórios com alta qualidade tecnológica, o Complexo Esportivo encarna o desejo do Catar de "crescer como um ator mundial no mundo esportivo, misturando criatividade $\mathrm{e}$ desenvolvimento ao talento individual dos atletas". ${ }^{15}$

$(2014)^{16}$

\begin{tabular}{l|c}
\hline TORNEIOS & ANO \\
\hline JOGOS DO OESTE DA ÁSIA (WEST ASIAN GAMES) & 2005 \\
\hline JOGOS ASIÁTICOS (ASIAN GAMES) & 2006 \\
\hline CAMPEONATO ASIÁTICO DE ATLETISMO INDOOR & 2008 \\
\hline CAMPEONATO INTERNACIONAL INTERCLUBES DE VOLEIBOL (FIVB) & 2009 \\
\hline CAMPEONATO MUNDIAL DE ATLETISMO INDOOR (IAAF) & 2010 \\
\hline COPA DA ÁSIA DE FUTEBOL & 2011 \\
\hline JOGOS ÁRABES & 2011 \\
\hline COPA DO MUNDO DE HANDEBOL (IHF) & 2015 \\
\hline CAMPEONATO MUNDIAL DE CICLISMO DE ESTRADA (UCI) & 2016 \\
\hline CAMPEONATO MUNDIAL DE GINÁSTICA ARTÍSTICA (FIG) & 2018 \\
\hline JOGOS OLÍMPICOS DE VERÃO (COI) - *CANDIDATURA NÃO VITORIOSA & 2020 \\
\hline COPA DO MUNDO DE FUTEBOL FIFA & 2022 \\
\hline
\end{tabular}

Tabela 1: Torneios Esportivos organizados pelo Catar recentemente - Fonte: Brannagan;Giulianotti.

Por outro lado, o desenvolvimento do doping institucionalizado na Rússia é um exemplo de malversação flagrante no campo esportivo, como demonstrado nos documentos produzidos pelo relatório McLaren de 2016. ${ }^{17}$ A descoberta da ação e a compreensão de como o estado liderado pelo presidente Vladimir Putin procedeu é eloquente. Este caso se inscreve em uma linhagem de outros eventos

\footnotetext{
${ }^{15}$ CAMPBELL. Staging globalization for national projects, p. 50.

${ }^{16}$ BRANNAGAN; GUILIANOTTI. Qatar, Global Sport, and 2022 FIFA World Cup, p. 32.

17 MACLAREN. Wada investigation of Sochi allegations, s/ pág.
} 
que ocorreram nos grandes regimes hegemônicos e totalitários do século XX Alemanha nazista, República Democrática Alemã (RDA), URSS, China comunista, Itália fascista, entre outros - na utilização do esporte como propaganda nacional. ${ }^{18}$ O sistema de doping institucionalizado é o exemplo mais radical do que se pode produzir através da instrumentalização do esporte e da ciência: a obtenção de resultados esportivos utilizando de todos os meios possíveis - lícitos e ilícitos tendo como objetivo único a vitrine política e geopolítica, não importando suas feridas e suas consequências futuras. ${ }^{19}$

Outro tema atual, embora a problemática seja milenar, diz respeito à relação entre o esporte como bom indicador de fluxo de migração, de políticas de imigração nacional e de trâmites e procedimentos de acesso à nacionalidade. Durante muito tempo, a Alemanha se privou de seus jogadores de origem estrangeira, notadamente aqueles de origem turca, até o momento no qual a legislação foi alterada, permitindo o recrutamento de atletas renomados como Masut Özil e Sami Khedira, peças fundamentais na Mannschaft. Neste mesmo contexto, percebemos inúmeros fluxos de imigração ao longo do século $\mathrm{XX}$, especialmente entre o norte da África em direção à França, viabilizando o surgimento de gerações Kopa, Platini, Zidane e Progba. ${ }^{20}$

Outro fator essencial é a atração de determinadas Nações por atletas renomados, em outras palavras, a política de naturalização de talentos esportivos. Como exemplo máximo, podemos citar o caso do Catar no contexto do handebol. Aos 27 dias de janeiro de 2011, a Federação Internacional de Handball conferiu ao Catar a organização do Campeonato Mundial de Handball Masculino 2015. Tendo em vista a grande possibilidade de projeção/visibilidade internacional, o Catar constituiu uma equipe formada essencialmente por jogadores naturalizados às pressas. Dos 19 atletas convocados, somente dois eram nativos do país. Com essa equipe, o Catar foi o primeiro país não-europeu a disputar uma final do campeonato, sendo vencido pela França. Esse fato foi amplamente divulgado nos

\footnotetext{
${ }^{18}$ GYGAX, Diplomatique culturelle et sportive américaine,sempágina.

${ }^{19}$ GILLON. Une lecture géopolitique du sytèmeolympique, sempágina.

${ }^{20}$ Para maiores informações sobre este tema no contexto francês, sugerimos o documentário LesBleus: une autrehistoire de France 1996-2016, dirigido por Sonia Dauger, Pascal Blanchard e David Dietz, lançado em 2016.
} 
jornais internacionais como exemplo de uso dos megaeventos como soft-power. ${ }^{21}$ Segundo especialistas, o discreto emir Tamim bin al-Thani é um entusiasta do softpower, que permite "influenciar as relações internacionais de maneira mais branda". ${ }^{22}$

\section{ESPORTE COMO INDICADOR GEOPOLÍTICO DE PODER DE UMA NAÇÃO: DO SEU PAPEL À SUA INFLUÊNCIA INTERNACIONAL}

O esporte, para além do que já foi discutido, aparece como um importante revelador da capacidade de expansão de uma nação, da sua habilidade de atrair novos investimentos e da sua posição estratégica no mundo globalizado. Nos dias de hoje, o esporte permite aos países uma situação afora da existência, ele outorga um posicionamento planificado e uma habilidade de abertura do raio de ação. 0 Azerbaijão ${ }^{23}$ e o Cazaquistão, à semelhança da China e Catar, têm conduzido políticas de influência e de expansão territorial via esporte de maneira refletida e estratégica. Neste aspecto, vale lembrar que a última edição da final da Liga Europa, temporada 2018/2019, opondo Arsenal e Chelsea, ocorreu em Baku, ${ }^{24}$ capital do Azerbaijão, comprometendo a escalação do jogador armênio, Mkhitaryan, pela não garantia de sua segurança em território azerbaijano. ${ }^{25}$ Mais

\footnotetext{
${ }^{21}$ Joseph S. Nye Jr, em 1990, no seu livro Boundto Lead: The Changing Nature of American Power (NYE, 1990), e depois em uma série de artigos e outras publicações reinterpretaria a noção de poder na política internacional (NYE, 2004;2008), dividindo-o em duas grandes categorias, Hard e Soft, termos que em pouquíssimo tempo se consagrariam, tanto na academia quanto na própria política, sendo inclusive tema de discursos dos mais variados líderes internacionais. A noção de Hard Power pode ser definida de uma maneira direta, sendo a capacidade de coerção de uma nação sobre as outras. Soft Power é definido como, a forma de um país obter resultados na política internacional, porque os outros países admiram seus valores e aspiram o seu nível de prosperidade e acabam por segui-lo. Para o autor, o poder nas relações internacionais é a capacidade de um país conseguir os resultados na política internacional e isso pode ser feito por meio da coerção (Hard Power) ou da cooptação (Soft Power). Nye irá dividir as fontes de Soft Power em três elementos principais: (1) a cultura, (2) os valores políticos e (3) a política internacional.

${ }^{22}$ DJAMSHIDI. Neymar au PSG, p. 1.

${ }^{23}$ Há uma década que o país de 10 milhões de habitantes no Cáucaso vem aproveitando dos seus recursos naturais (petróleo) para se destacar através do esporte. É também uma maneira do país, governado desde a queda da União Soviética pela família Aliev, de maquiar as violações de direitos humanos das quais é continuamente acusado (LOBO, 2019).

${ }^{24} \mathrm{Baku}$, capital do Azerbaijão, candidatou-se duas vezes para sediar os Jogos Olímpicos de 2016 e 2020, perdendo respectivamente para a cidade do Rio de Janeiro e Tóquio. No entanto, sediou os Jogos Europeus de 2015, no estádio Olímpico de Baku construído nesta ocasião, além da organização de uma das etapas da Fórmula 1. Para a Eurocopa de 2020, que não terá um país fixo, a capital sediará três partidas da fase de classificação e um jogo das quartas de final (LOBO, 2019).

${ }^{25}$ PEREZ. Por conflito político, s/ pág.
} 
uma vez, tocamos em uma das novas dimensões da geopolítica contemporânea, aquela do soft-power esportivo no seu sentido lato, ou seja, no uso do esporte de maneira pensada como uma alavanca de poder suplementar na esteira de uma política externa clássica.

Além da influência que o esporte oferece à abertura de um raio de ação de uma nação, ele se impõe como um elemento identitário forte. 0 fato esportivo é um elemento essencial de afirmação dos atores mundiais pela sua capacidade de representar um território qualquer e por reencarnar atributos nacionalistas, em outras palavras, identidades locais. Portador de representação, fator de unidade interna, seja em plano local ou internacional, o fenômeno esportivo revela a construção e a difusão de uma identidade sobre um território apropriado, preparado e valorizado. Isso dito, o esporte se inscreve como uma chave na construção nacional dos estados-nações. O Afeganistão, por exemplo, encontrou uma nova posição no cenário mundial por meio do esporte, especialmente o críquete. A Palestina, que não é reconhecida como um estado-membro da ONU, é integrante da FIFA e utiliza o esporte para realçar sua unidade, malgrado sua relação complexa e turbulenta com o estado de Israel.

Neste contexto, o esporte pode servir como vitrine de uma maestria de valorização e organização de um determinado país. Considerando que o esporte predispõe uma relação particular junto ao espaço urbano que ele ocupa, ele é um marcador e uma medida da capacidade e do poderio de um estado quanto à utilização proveitosa de implementação de serviços no campo esportivo. Quer tenhamos como exemplo o Estádio de Wembley, em Londres, o Maracanã no Rio de Janeiro, ou a ampliação do complexo esportivo de Roland Garros, em Paris, toda construção de uma infraestrutura esportiva responde à lógica de planificação e à uma estratégia de ordenamento de territórios que demonstram a habilidade de diversos atores e instituições esportivas na organização conjunta de uma proeza esportiva. Com efeito, trata-se de um novo vestígio da relação estreita entre esporte e geopolítica em escala local alcançando consequentemente dimensões mundiais.

Ilustremos através do caso dos JO de Inverno de Turim organizado no ano de 2006. A aproximação dos jogos foi pensada estrategicamente e de maneira manifesta em termos geopolíticos. Preconizado como "um processo dotado de uma 
organização precisa cujas dimensões espaciais e temporais interagiriam intensamente [...] o espaço afetado pelo megaevento foi utilizado como catalisador de investimentos e sofrendo alterações constantes para se adaptar aos objetivos do projeto". ${ }^{26}$ Tudo isto mostrou a capacidade do estado italiano, bem como da cidade de Turim, de transformar um território em uma força política. A organização do megaevento proporcionou um aumento da atratividade internacional da cidade, ampliou seu raio de ação em termos comerciais, estrategicamente locado no pensamento de uma perenidade do território. ${ }^{27}$

O contraexemplo deste sucesso pode ser visto na organização megalomaníaca dos J0 de Inverno de Sóchi em 2014. Projeto vasto vislumbrando a valorização do território caucasiano em diversos aspectos, os JO de Inverno russo visavam tanto objetivos geopolíticos, quanto econômicos, utilizando de meios colossais (mais de 45 bilhões de euros). No entanto, a vigésima segunda olimpíada de inverno foi uma decepção e ficou aquém de deixar uma marca na reorganização do território no longo prazo. Os JO de Sóchi atestaram a vontade incomensurável da Rússia de se fazer resplandecer no curto prazo, não obstante, no transcorrer do tempo, a organização dos jogos se transformou em uma estratégia impotente no âmbito da política esportiva.

Da maneira similar, o fato de atrair os maiores eventos esportivos mundiais para o seu território se impõe como uma demonstração de poder dos estados e demonstra sua capacidade de pensar e refletir, a seu próprio benefício, das grandes decisões que permeiam o campo esportivo. Diretamente relacionado à valorização do território, mas não somente isto, a escolha de um país, ou cidade, em detrimento de outro, escancara mais uma vez aspectos geopolíticos. A FIFA e o COI não podem negar que suas escolhas foram e são orientadas estrategicamente pelo viés político e/ou geográfico. Efetivamente, quando analisamos os mecanismos de designação, percebemos que aspectos econômicos, políticos, ambientais, sociais, entre outros, são analisados de maneira similar às análises dos dossiês de candidaturas. A escolha da África do Sul em 2010 para a organização da

\footnotetext{
${ }^{26}$ DANSERO; MELA. La territorialisation olympique, p. 11.

${ }^{27}$ Neste aspecto, os JO de Barcelona são igualmente notórios e reconhecido, pelos especialistas, como modelo de transformação urbana via megaevento, embora problemas de gentrificação e expropriação tenham sido frequentes (CASTILHO, 2016).
} 
CM de futebol, ou em 1995, para a CM de rúgbi, ilustra plenamente a ideia de um país emergente em termos econômicos e o retorno pós-apartheid do país na cena internacional. Certamente, estes dois fatores pesaram de forma justa junto à qualidade do dossiê local.

Eventos geopolíticos mundiais influenciam sobremaneira as decisões sustentadas pelo COI desde a escolha da primeira sede dos J0, em 1896, na cidade de Atenas, Grécia. Embora o COI sustente a ideia de imparcialidade e não influência política no que concerne suas deliberações, sabe-se que o contexto mundial guerras, tratados, aspectos sociais e econômicos, disputas políticas, entre outros dita as suas relações, predileções e resoluções finais. A título de exemplo, pode-se citar a escolha da cidade de Berlim em 1936, de Tóquio em 1964, da cidade do México em 1968, de Moscou em 1980, de Seul em 1988, de Barcelona em 1992, de Atlanta em 1996, de Pequim em 2008 e do Rio de Janeiro em 2016. Estudos demonstram como fatores geopolíticos mundiais foram preponderantes nestas decisões, ${ }^{28}$ sobrepondo quaisquer aspectos técnico ou racional. 0 COI, contrariamente ao discurso dos seus diretores, vincula sua decisão ao contexto político em detrimento de uma candidatura de qualidade, na qual gastos, legados e transparência deveriam servir como critérios primários.

Atualmente, percebemos uma mudança de postura dos órgãos responsáveis pelos megaeventos uma vez que o número de candidatas a cidades-sede vem diminuindo e que os legados desses eventos veem sendo questionados por pesquisadores. Este é o caso dos JO, tanto os de verão, quanto os de inverno. De maneira inédita, o COI votou pela dupla atribuição dos JO de 2024, Paris, e 2028, Los Angeles, visto que quatro candidaturas prévias - Boston (EUA), Hamburgo (ALE), Roma (ITA), Budapeste (HUN) - foram retiradas anteriormente ao 131음 Congresso do COI, realizado no dia 13 de setembro 2017, na cidade de Lima (Peru), momento durante o qual a instituição máxima dos JO decidiria pela cidade-sede dos JO 2024.

O esporte desvela dessa forma as diferentes facetas do poder tradicional dos estados-nações e suas hierarquias, bem como suas relações e rivalidades, no

${ }^{28}$ BONIFACE. JO politiques, s/ pág. GOLDBLATT. The Games, a global history of the Olympics, s/ pág. 
momento presente e ao longo do tempo. Ele permite simplesmente a captura - ou a percepção - da articulação de diferentes componentes relacionados às políticas de poder de um país. Por isto, o esporte pode e deve ser considerado como um objeto geopolítico. Sobretudo porque ele é um revelador de poder político e um fator de criação, de apropriação e/ou reconstrução de representações geopolíticas vis-à-vis dos fatores internos e que são destinados a outros elementos externos.

O objeto esportivo torna-se então legítimo na abordagem geopolítica, pois ele faz jus a exatamente aquilo que ele se propõe e aquilo que ele permite compreender. Para além de um simples elemento circunscrito no soft-power, nós poderíamos atualmente nomeá-lo como sportpower puramente. ${ }^{29}$

\section{À GUISA DE CONCLUSÃO: ESPORTE UM INSTRUMENTO DE ANÁLISE GEOPOLÍTICA A RELATIVIZAR}

O esporte é um termômetro das relações internacionais. É preciso que as condições estejam reunidas a montante, e que os Estados tenham de antemão desejo de fazer evoluir suas políticas externas. Não foi o pingpong que levou à reaproximação entre os Estados Unidos e a China, pois esta política já vinha sendo imaginada e estruturada desde os anos 1960. Estes eventos servem no melhor dos cenários como símbolos importantes, e no pior como pretexto para algo. ${ }^{30}$

A despeito de todo o interesse que gostaríamos de lhe associar e toda importância que desejaríamos lhe conceder, o esporte, como critério de relações de poder contemporâneo, não possui nem o mesmo peso, nem o mesmo valor, que os aspectos militares ou nucleares, por exemplo. Dessa forma, ao falarmos de esporte, sempre precisamos relativizar. Estas reservas, notadamente sublinhadas pelo geopolítico Frédéric Encel, se devem ao fato do esporte ser frequentemente o resultado de outros elementos componentes do poderio de um estado.

O fato de um país ter uma economia pulsante e globalizada viabiliza e permite o desenvolvimento do esporte, não obstante, o contrário não é factível. Idem, o esporte, através do seu aspecto sistemático e plural, é tributário de diversos fatores de poder combinados. Mais facilmente apreendido pelo mundo, o

\footnotetext{
${ }^{29}$ GUÉGAN. Géopolitique du sport,sempágina.

${ }^{30}$ GOLDBAUM. La diplomatique du ping-pong fait son retour au Qatar, p. 3. Entrevista com Paul Dietschy, pesquisador associado do Centro de Pesquisas em História da Sciences-Po e professor da disciplina História do Esporte (Sciences-Po, Paris, França).
} 
esporte tem o mérito de ser mais claro e acessível que outras formas de poder, tal qual o poder nuclear. 0 esporte atinge e impressiona com mais aferro o imaginário coletivo, sem a necessidade de coagir, comportando igualmente uma carga simbólica compreendida e considerada no seu devido momento.

O esporte, na política contemporânea, desempenha o seguinte papel: reforçar o poder impressionando os espíritos. Pequenas e grandes Nações aventuram-se neste jogo. Nada mais importante, aos olhos da China, do que se passar por uma grande potência esportiva e, se possível, ultrapassar os Estados Unidos no quadro de medalhas olímpicas! A frontline da Guerra Fria, entre a URSS e os EUA, passava necessariamente pelo esporte. E não acreditemos que, com a extinção da URSS, e o novo sistema capitalista dominante no mundo, o jogo esportivo em termos de poder tenha desaparecido. Os Estados sabem muito bem que o esporte é a chave do imaginário do homem contemporâneo. Enfim, o esporte é utilizado para aumentar o poder imaginário de um determinado Estado. ${ }^{31}$

Por si mesmo, a partir da linha de pensamento de Robert Redeker, o esporte acompanha a história do poder global. Ele reflete este poder e possibilita igualmente a sua apreensão. Podemos considerá-lo como um marcador, um indicador, um fator, mas não como uma alavanca que, através das suas consequências, promoveria mudanças geopolíticas eloquentes. É preciso, dessa maneira, pensá-lo e aproximá-lo sob a égide geopolítica, colocando-o nas análises de acordo com a sua grandeza. ${ }^{32}$ Uma partida de críquete entre o Paquistão e a Índia não é capaz de alterar a condição de suas relações conflituosas, mesmo que permita o estabelecimento de um novo diálogo, como foi o caso da diplomacia do ping-pong entre a China de Mao e os EUA de Nixon. Similarmente, a organização da CM 2010 não permitiu à África do Sul alterar profundamente sua sociedade ou o seu lugar no mundo. Quanto ao Catar, o fato de ser o proprietário do Paris SaintGermain (PSG) via QIA (Qatar Investment Authority), fundo de investimentos soberano, não lhe permite uma vantagem estratégica maior vis-à-vis seu vizinho Saudita no contexto do conflito que os opõem desde junho 2017. Mais recentemente, os JO de Inverno na Coréia do Sul foram igualmente utilizados como forma de aproximação à Coréia do Norte. Para além do desfile conjunto na

\footnotetext{
${ }^{31}$ REDEKER.Le sport contre les peuples, p. 34-35.

${ }^{32}$ GUÉGAN. Géopolitique du sport, s/ pág.
} 
abertura dos Jogos, ${ }^{33}$ as duas Coreias disputaram sob a mesma bandeira a modalidade de hóquei no gelo. ${ }^{34}$

Desse modo, a geopolítica do esporte permite a mensuração da expressão de um determinado poder estatal, incorporando o esporte como um dos seus componentes. A geopolítica é o reflexo desse jogo de poder que ela mesma decodifica ao mesmo tempo em reflete os seus próprios limites de análise. Demandar mais do que isso do campo geopolítico esportivo seria excessivo e presumiria uma importância exagerada no que tange o esporte.

Falar de geopolítica do esporte é extremamente relevante, mas, através das suas análises, faz-se necessário saber relativizar sua amplitude e sua eficiência. Pelo seu aspecto elitista e seletivo, o esporte global só diz respeito àqueles atores que estão destacados e que se impõem neste meio. Por si mesmo, o esporte, pelo que o implica, opera uma seleção. Esta distinção revela uma hierarquia do mundo e dos seus locais mais poderosos, excluindo a maior parte dos indivíduos e os colocando em posição periférica. Tal prisma nos coloca outro limite de sistematização para que um critério de análise em geopolítica do esporte seja factível, ou seja, uma leitura fiel do mundo contemporâneo. A geopolítica do esporte "operaria ao mesmo tempo como um espelho ampliado, mas igualmente como um fator de exclusão demasiado superficial". ${ }^{35}$ Ela favoreceria as potências ao adquirir o papel de vetor de afirmação de um determinado poder sobrepondo com mais eficiência outros. Os estados são evidentemente os primeiros atores e beneficiários dessa aproximação geopolítica, mas, concomitantemente, as empresas transnacionais (financiadoras), as organizações não-governamentais (organizadoras - FIFA, COI, etc.), outras ligas privadas e as empresas midiáticas globais de difusão, lucram e se beneficiam demasiadamente do campo esportivo. Tais benefícios, evidentemente, acarretam na exclusão de outros diversos atores.

\footnotetext{
${ }^{33}$ O desfile em conjunto já havia ocorrido nos JO de Sidney em 2000, nos JO de Atenas 2004 e nos JO de Inverno de Turim em 2006 (RICH, 2018).

${ }_{34} \mathrm{RICH}$. Olympics open with Koreas marching together,sempágina.

${ }^{35}$ GUÉGAN. Géopolitique du sport,p. 88.
} 


\begin{tabular}{ll}
\hline PAÍS ORGANIZADORIAno & CUSTO FINAL (em dólar) \\
\hline QATAR 2022* $^{*}$ & 200 bilhões * previsão segundo Touzri (2013) \\
RUSSIE 2018* & 20 bilhões * informações conflitantes \\
BRESIL 2014 & 15 bilhões \\
AFRIQUE DU SUD 2010 & 3 bilhões \\
ALLEMAGNE 2006 & 600 milhões \\
FRANCE 1998 & 500 milhões \\
\hline
\end{tabular}

Tabela 2: Custo final das Jogos Olímpicos de Verão- Fonte:Pouchard;Bellanger(2017).36

\begin{tabular}{ll}
\hline PAÍS ORGANIZADORIAno & CUSTO FINAL (em euros) \\
\hline RIO DE JANEIRO 2016 & 16,5 bilhões de $€$ \\
LONDRES 2012 & 11 bilhões de $€$ \\
PÉQUIN 2008 & 31 bilhões de $€$ \\
ATENAS 2004 & 10 bilhões de $€$ \\
SIDNEY 2000 & 5,5 bilhões de $€$ \\
ATLANTA 1996 & 2,3 bilhões de $€$ \\
BARCELONA 1992 & 9,3 bilhões de $€$ \\
SEUL 1988 & 4,2 bilhões de $€$ \\
\hline
\end{tabular}

Tabela 3: Custo final das últimas Copas do Mundo - Fonte: Castilho (2016, p. 45). ${ }^{37}$

Atualmente, quando comparamos os custos relacionados ao acolhimento e organização dos JO e das Copas do Mundo desde 1980 (mesmo corrigindo a inflação), percebemos uma verdadeira explosão nos gastos (Tabela 2). As olimpíadas custam 12 vezes mais nos dias de hoje (Tabela 3). Rússia, China e Brasil precisaram desembolsar quantias inimagináveis em determinados momentos para reestruturar seus equipamentos esportivos e infraestruturas em geral. No que tange à $\mathrm{CM}$ de futebol, um acréscimo exorbitante relacionado à segurança e à mundialização do evento provocou um aumento real de cinco vezes no seu gasto. Deste modo, constatamos que nada menos que $90 \%$ dos países do mundo encontram-se excluídos de facto da organização dos dois maiores eventos esportivos globais. Hodiernamente, uma parcela de pouco mais de 15 países pode sonhar com a possibilidade de acolher um megaevento, obviamente, respeitando seus respectivos interesses e intenções. Com essa linha de análise, deixamos em aberto novas incursões e, porque não dizer, novas possíveis correlações teóricas para o estudo do esporte no campo da geopolítica.

\footnotetext{
${ }^{36}$ POUCHARD; BELLANGER. Les Jeux olympiques, sempágina.

${ }^{37}$ CASTILHO. Politiques publiques et la Coupe du monde de football 2014 au Brésil, p. 45.
} 


\section{REFERÊNCIAS}

ARON, Raymond. Le spectateur engagé: entretiens avec Jean-Louis Missika et Dominique Wolton. Paris: Presse Pocket/Julliard, 1983.

BOLZ, Daphné. Les arènes totalitaires: Hitler, Mussolini et les jeux du stade. Paris: CNRS Éditions, 2008.

BONIFACE, Pascal. JO Politiques: sport et relations internationales. Paris: Eyrolles, 2016.

BOURDIEU, Pierre. A distinção: crítica social do julgamento. $2^{\circ}$ Edição. ed. Rio de Janeiro: Editora Zouk, 2006.

BRANNAGAN, Paul Michael; GIULIANOTTI, Richard. Qatar, Global Sport, and the 2022 FIFA World Cup. In: GRIX, Jonathan. Leveraging Legacies from Sports Mega-Events. Basingstoke: Palgrave, 2014.

CAMPBELL, Rook. Staging Globalization for National Projects: Global Sport Markets and Elite Athletic Transnational Labour in Qatar. International Review for the Sociology of Sport, v. 46, n. 1, p. 45-60, 2010.

CASTILHO, César Teixeira. Politiques Publiques et la Coupe du monde de football 2014 au Brésil: des espoirs aux héritages locaux. Paris, 2016, $556 \mathrm{f}$. Tese (Doutorado em Sciences du Sport et du Mouvement Humain). Sciences et techniques des activités physiques (STAPS), Université de Paris-Sud (Paris 11).

DANSERO, Egidio; MELA, Alfredo. La territorialisation olympique: le cas des jeux de Turin, 2006. Revue de géographie alpine, v. 95, n. 3, p. 1-15, 2007.

DJAMSHIDI, Antoine. Neymar au PSG: Nasser Al-Khelaïfi promet de "gros changements", Laurent Blanc peut-être menacé. Le Parisien, 03 jun. 2016.

GILLON, Pascal. Une lecture géopolitique du système olympique. Annales de Géographie, v. 4, n. 680, p. 425-448, 2011.

GINESTA, Xavier; EUGENIO, Jordi de San. The Use of Football as a Country Branding Strategy: Case Study: Qatar and the Catalan Sports Press. Communication \& Sport, v. 2, n. 3, p. 225-241, 2013.

GOLDBAUM, Maxime. La diplomate du ping-pong fait son retour au Qatar. Le Monde Web Site, 2011. Disponivel em: https://bityli.com/sXoVQ. Acesso em: 04 jun. 2019.

GOLDBLATT, David. The Games: A Global History of the Olympics. New York and London: Norton, 2016.

GUÉGAN, Jean-Baptiste. Géopolitique du sport: une autre explication du monde. Paris: Breal, 2017.

GYGAX, Jérôme. Diplomatie culturelle et sportive américaine: persuasion et proagande durant la Guerre froide. Relations Internationales, v. 3, n. 123, p. 87-106, 2005.

LACOSTE, Yves. Dictionnaire de Geopolitique. Paris: Flammarion, 1999. 
LOBO, Felipe. Da Euro 2020 à F1: Baku, mergulhada em controvérsia, é símbolo do Azerbaijão que se promove para o mundo. Trivela Web Site, 2019. Disponivel em: https://bityli.com/t9Kc4. Acesso em: 04 jun. 2020.

MARCHI JR, Wanderley. O "Esporte em Cena": perspectivas históricas e interpretações conceituais para a construção de um Modelo Analítico. The Journal of the Latinamerican Socio-Cultural Studies of Sport, Curitiba, v. 5, n. 1, p. 46-67, 2015.

MCLAREN, Richard. WADA Investigation of Sochi Allegations. World AntiDoping Agency. Montreal, p. 144. 2016.

MILZA, Pierre. Sport et relations internationales. Relations Internationales, $\mathrm{n}$. 38, p. 155-174, 1984.

NYE, Joseph. Bound to lead: the changing nature of American Power. New York: Basic Book, 1990.

PÉREZ, Gorka. Por conflito político, Arsenal anuncia que não levará jogador armênio à final da Liga Europa no Azerbaijão. El País Web Site, 2019. Disponivel em: https://bityli.com/u7EFe. Acesso em: 04 jun. 2020.

POUCHARD, Alexandre; BELLANGER, Elisa. Les Jeux olympiques, un budget difficile à maîtriser. Le Monde Web Site, 2017. Disponivel em: https://bityli.com/yODjr. Acesso em: 25 jun. 2020.

REDEKER, Robert. Le Sport contre les peuples. Paris: Berg International, 2002.

$\mathrm{RICH}$, Motoko. The New York Times. Olympics Open With Koreas Marching Together, Offering Hope for Peace, 2018. Disponivel em: https://bityli.com/0zmLp. Acesso em: 24 jun. 2020.

TOUZRI, Michel. Ça coûte combien une Coupe du Monde de football? Paris Sportifs, 2013. Disponivel em: https://bityli.com/SUX3H. Acesso em: 25 jun. 2020. 